\title{
ScIDic
}

\author{
International Journal of Dentistry and Oral Science (IJDOS) \\ ISSN: 2377-8075
}

\section{Knowledge Of Osteoporosis Among Students Of Private Dental College In Chennai}

Research Article

Palak Shah ${ }^{1}$, Lakshmi Thangavelu ${ }^{*}$

${ }^{1}$ Department of Pharmacology, Saveetha Dental College and Hospitals, Saveetha Institute of Medical and Technical Sciences, Saveetha University, Chennai, India.

\section{Abstract}

The aim is to evaluate knowledge and perceptions of osteoporosis among university students in Chennai belonging to different age groups, gender and ethnicity. To infer whether the students of Saveetha Dental College in Chennai have knowledge about osteoporosis. This research was based on a questionnaire This survey-based research was done to spread awareness about osteoporosis among the students of Saveetha Dental College, Chennai. This article showed that students of Saveetha Dental College needed more awareness camps to create more awareness.

Keywords: Osteoporosis; Awareness; Knowledge; Women; Dental College.

\section{Introduction}

The National Osteoporosis Foundation describes osteoporosis as a 'silent disease' and it is a generic term which is used to define the reduction in mass and increased porosity of the skeleton that alters fracture risk [1]. Osteoporosis is a major and growing public health problem in both gender but particularly in women. It is estimated that the proportion of women with osteoporosis increases from $15 \%$ with in the age group 60 to 64 years up to $71 \%$ in those over 80 years of age $[2,3]$.

It is often a slow, steady but undetected development during adulthood and particularly during the older age as the balance between bone formation and resorption shifts in favour of resorption. Acquisition of peak bone mass which occurs during the first three decades and the subsequent retention of bone through middle age are important determinants for reducing the risk of osteoporosis. The etiology of osteoporosis is multifactorial. General calcium and vitamin D supplementation to the elderly in nursing homes has been proven efficient in reducing fracture incidence and may be of health-economic importance [4-6].

It is important to improve the awareness and knowledge of osteoporosis and its prevention measures as osteoporosis is a disease which can be prevented. Health care providers need to determine the population's knowledge of and attitudes towards osteoporosis to plan effective education programs. One of the first steps for raising awareness and planning education is to examine how much is known about the disease by those who have the disease and by the lay public [7]. Therefore; the aim of this study is to evaluate the awareness, perception, sources of information, and knowledge of osteoporosis among the students which handle the general pathology of the body. Studies have shown that planning for osteoporosis prevention requires sufficient information about people's health knowledge and beliefs. Meanwhile for early diagnosis of the disease, awareness of osteoporosis symptoms helps and encourages help-seeking behaviors and decreases the disease complications.

Due to devastating consequences of osteoporosis, it demands a huge expense for diagnosis, treatment as well as management of its complications it is no longer considered as only a public health concern, rather it has emerged as a socio-economic issue. Major determinant symptoms of osteoporosis includes fragility fractures, among which most common one are hip fractures followed by severe acute back pain, vertebral and wrist fracturesloss of height (dowager's hump), limitation of mobility and stooped posture (kyphosis) in chronic severe cases. Though osteoporosis quietly develops over years, most considerable risk factors includes genetics, being female especially postmenopausal women,

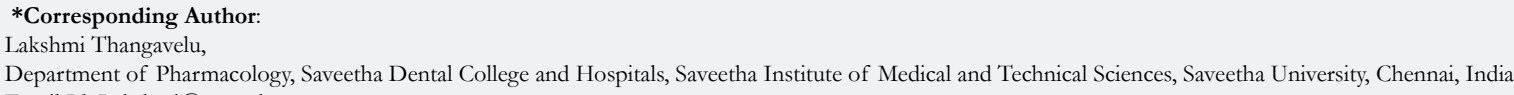

Copyright: Lakshmi Thangavelu 2021. This is an open-access article distributed under the terms of the Creative Commons Attribution License, which permits unrestricted use, distribution and reproduction in any medium, provided the original author and source are credited. 
advance age, petite body structure, low consumption of calcium and vitamin $\mathrm{D}$, lack of exposure to sunlight, sedentary life style, chronic ingestion of alcohol $[8,9]$.

Several risk factors for osteoporosis have been recognised. These include female sex, race, advancing age, family history of osteoporosis or fragility fractures, a low body mass index, menopause before age 45 years, delayed amenorrhea unrelated to menopause, prolonged lactation, diet low in calcium and vitamin $\mathrm{D}$, poor intestinal absorption of calcium, lactose intolerance, excessive caffeine or alcohol consumption; smoking, sedentary life style, and prolonged treatment with thyroid hormones, glucocorticoids, anticonvulsants, aluminium antacids, and use of anticoagulants, therefore, the present study was designed and performed with the aim of determining the awareness of dental students in relation to osteoporosis.

\section{Materials and Methods}

The materials and methodology used in this study is a cross-sectional questionnaire based study. This prospective study was done in Saveetha Dental College, Chennai located in Southern India. It was carried out in December 2016. A cross-sectional, quantitative study was conducted based on a questionnaire containing 8 questions about prevention, clinical aspects, and attitudes towards osteoporosis. A total of 112 young and healthy undergraduates and postgraduates were selected for the present study, which consisted of both males and females of the university.

The survey included questions relating to socio-demographic characteristics, gynaecological history, height and weight (to calculate body mass index), overall health status and family history. Knowledge toward osteoporosis was assessed with a series of questions directed at the information women had heard and questioning sources where they received such information (e.g., television, radio, health care provider, etc). These questions were distributed among the dental students to help determine the knowledge and the attitude of osteoporosis.

\section{Results}

The following results obtained from the responders have been displayed below. The data obtained after the survey is studied and the results are verified. The available results have been formulated in the form of pie charts for better study.

The survey begins with the question enquiring the responders about the meaning of osteoporosis 38. of them believed it is a medical condition caused by lack of bone density, 22 considered it as bony protrusion appear in certain places. The rest 52 had different answers or did not know the meaning of osteoporosis. Osteoporosis occurring suddenly was believed by 27 of them and denied by the rest 84 .

In this cross sectional study, 42 of them agreed that females are more suspectible to osteoporosis than 8 males. Although, 62 of them were not sure about the gender. The most important question in our survey was the proper action of osteoporosis which is unknown to $80 \%$ of the responders. Taking calcium and vitamins supplementsand avoiding soft drinks is agreed by 32 of responders. Where as simple actions such as bed rest and follow up with doctors are also chosen as a better alternative.

When asked about likely bones which could break during osteoporosis, we could appreciate a mixed array of results 16 . thought pelvis bone, 10 thigh bone, 9 shoulder bone, 12 leg bone, 13 wrist bone. But $50 \%$ of responders did not have the knowledge that bones are broken during this disease. Osteoporosis is a disease which is believed by 42 responders to occur mainly during old age, 19 think at any particular age, 13 think during childhood and 9 think during middle age.

\section{Discussion}

Osteoporosis has recently been recognized as a major public health problem; it is no longer confined to the growing older population but has implications for all age groups. Hence increasing knowledge of osteoporosis should be a priority for future intervention programs in order to promote specific behavioural strategies for osteoporosis prevention. The purpose of this study was to explore the extent of osteoporosis knowledge and practices among dental students of Chennai students [10]. Regarding the risk factors for developing osteoporosis, results of the presents study revealed that the studied sample were aware of the risk factors that increase or cause osteoporosis include gender, family history, advancing age, post menopausal status and excess in soft drinks.

Primary osteoporosis is observed mainly in postmenopausal women and in elderly people. Secondary osteoporosis, on the other hand, is related to predisposing conditions such as genetic diseases, immobilization, idiopathic juvenile osteoporosis, medical treatment (i.e. corticosteroids, chemotherapeutics, heparin, lithium), endocrinological diseases, chronic alcoholism, haemotogenic diseases, chronic obstructive lung diseases, rheumatoid arthritis and malabsorption syndromes. Postmenopausal osteoporosis and osteoporosis of ageing are the commonest forms of the disorder. Postmenopausal osteoporosis expresses itself clinically as a fracture [11-14].

Fractures of the hip are 2-3 times more common in women than in men. With in the first year after hip fracture, there is a death rate of $5-20 \%$ in excess of that expected in control populations of a similar age. Age is known to be a major factor, affecting both male and female osteoporosis. It is also well known that bone mass declines with age and the reduction is more marked among women than men. As ageing progresses, localized imbalances appear with in each bone remodelling cycle, such that the amount of bone resorbed is greater than the quantity with which it is replaced, particularly on the endosteal surface of cortical bone and in cancellous bone. The disease has a strong genetic component. Current evidence suggests that the inheritance of bone mass is under polygenic control, but the genes responsible are poorly defined [15-19].

\section{Conclusion}

Although the majority of participants had a modest level of knowledge of osteoporosis, there were an adequate number of participants which had enough knowledge in relation to risk factors, protective factors and on the insidious nature of osteoporosis. Practices towards preventing Osteoporosis were adequate. Numerous drugs are currently available to treat osteoporosis and 
the choice of a specific compound should be guided by efficacy and safety considerations. People suffering from osteoporosis must have adequate nutrition, exercises daily in order to reduce risks and bone loss. The risk of developing osteoporosis and /or incurring a fracture can be lowered by preventive lifestyle measures and drug treatments that protect against bone loss and encourage healthy bone mineralisation. This shows that people need have more awareness towards osteoporosis and more awareness camps should be held.

\section{References}

[1]. Ungan M, Tümer M. Turkish women's knowledge of osteoporosis. FamPract. 2001 Apr 1;18(2):199-203.

[2]. Winzenberg TM, Oldenburg B, Frendin S, Jones G. The design of a valid and reliable questionnaire to measure osteoporosis knowledge in women: the Osteoporosis Knowledge Assessment Tool (OKAT). BMC MusculoskeletDisord. 2003 Jul 24;4:17.Pubmed PMID: 12877751.

[3]. von Hurst PR, Wham CA. Attitudes and knowledge about osteoporosis risk prevention: a survey of New Zealand women. Public Health Nutr. 2007 Jul;10(7):747-53.Pubmed PMID: 17381949.

[4]. Waller J, Eriksson O, Foldevi M, Kronhed AC, Larsson L, Löfman O, et al. Knowledge of osteoporosis in a Swedish municipality--a prospective study. Prev Med. 2002 Apr;34(4):485-91.Pubmed PMID: 11914055.

[5]. Gemalmaz A, Oge A. Knowledge and awareness about osteoporosis and its related factors among rural Turkish women. ClinRheumatol. 2008 Jun;27(6):723-8.Pubmed PMID: 17965905

[6]. Riaz M, Abid N, Patel J, Tariq M, Khan MS, Zuberi L. Knowledge about osteoporosis among healthy women attending a tertiary care hospital. J Pak Med Assoc. 2008 Apr;58(4):190-4.Pubmed PMID: 18655428.

[7]. Geller SE, Derman R. Knowledge, beliefs, and risk factors for osteoporosis among African-American and Hispanic women. J Natl Med Assoc. 2001
Jan;93(1):13-21.Pubmed PMID: 12653376.

[8]. Bernabei R, Martone AM, Ortolani E, Landi F, Marzetti E. Screening, diagnosis and treatment of osteoporosis: a brief review. Clin Cases Miner Bone Metab. 2014 Sep;11(3):201.

[9]. Hannon C, Murphy K. A survey of nurses' and midwives' knowledge of risks and lifestyle factors associated with osteoporosis. J. Orthop. Nurs. 2007 Feb $1 ; 11(1): 30-7$.

[10]. Mansoureh S, Elahe A, Hossein S. Awareness of osteoporosis among female employees in Kerman, Iran. Russ. Open Medical J. 2015;4(1):e0103.

[11]. Senapati J. et al. 'Risk Factors of Osteoporosis among Post Menopausal Women', International Journal of Contemporary Medical Research [IJCMR]; 2018. DOI: 10.21276/ijcmr.2018.5.4.22

[12]. Abdullah WH. Risk factors and preventive measures awareness among nursing students regarding osteoporosis. IOSR Nurs Health Sci . 2017;6(2):7-21.

[13]. Juby AG, Davis P. A prospective evaluation of the awareness, knowledge, risk factors and current treatment of osteoporosis in a cohort of elderly subjects. Osteoporos Int. 2001;12(8):617-22.Pubmed PMID: 11580074.

[14]. Bukowska-Damska A, Skowronska-Jozwiak E, Kaluzny P, Lewinski A, Peplonska B. Night shift work and osteoporosis among female blue-collar workers in Poland-a pilot study. Chronobiol Int. 2020 Jun 2;1-11:25.

[15]. Shilbayeh S. Prevalence of osteoporosis and its reproductive risk factors among Jordanian women: a cross-sectional study. Osteoporos Int. 2003 Nov;14(11):929-40.Pubmed PMID: 14530908.

[16]. Rankin DM, Kruger MC, Stonehouse W. Analysis of bone mineral density and osteoporosis risk in Manawatu, New Zealand. Bone. 2009(44):S120.

[17]. Parker MJ, Gillespie WJ, Gillespie LD. Effectiveness of hip protectors for preventing hip fractures in elderly people: systematic review. Bmj. $2006 \mathrm{Mar}$ 9;332(7541):571-4.

[18]. Swiontkowski MF. 'Effectiveness of hip protectors for preventing hip fractures in elderly people: Systematic review', Yearbook of Orthopedics. 2007;82-83. DOI: 10.1016/s0276-1092(08)70085-3.

[19]. Parker MJ, Gillespie WJ, Gillespie LD. Hip protectors for preventing hip fractures in older people. Cochrane Database Syst. Rev. 2005(3). 